\title{
The (partial) rehabilitation of interest rate parity in the floating rate era: Longer horizons, alternative expectations, and emerging markets
}

\author{
Menzie D. Chinn ${ }^{\text {a,b,* }}$ \\ ${ }^{a}$ Robert M. La Follette School of Public Affairs and Department of Economics, \\ University of Wisconsin, Madison, WI, USA \\ ${ }^{\mathrm{b}}$ NBER, Cambridge, MA, USA
}

\begin{abstract}
This paper examines several new empirical findings in the study of uncovered interest parity. It reviews recent developments in the study of long-horizon interest parity regressions, the implications of relaxing the rational expectations methodology and the characteristics of results pertaining to the non-G7 currencies, including those in less developed economies. In brief, the evidence against uncovered interest parity in the current floating rate era is not as great as is commonly thought, although it is still true that for the major currencies, the short-term interest differential remains a biased predictor of ex post changes in the exchange rate. (C) 2005 Elsevier Ltd. All rights reserved.
\end{abstract}

JEL classification: $\mathrm{F} 31 ; \mathrm{F} 41$

Keywords: Uncovered interest parity; Unbiasedness hypothesis; Rational expectations; Exchange rates; Financial market integration; Emerging markets; Survey data

\section{Introduction}

It is widely believed that uncovered interest parity (UIP) is a useful theoretical concept, but an empirically irrelevant construct. This belief is understandable, given the widespread failure

\footnotetext{
* Department of Economics, 7470 Social Sciences Building, University of Wisconsin, 1180 Observatory Drive, Madison, WI 53706, USA. Tel.: +1 608262 7397; fax: +1 6082622033.

E-mail address: mchinn@lafollette.wisc.edu
} 
to find evidence that ex post changes in exchange rates should be positively related to interest differentials with a coefficient of unity. However, as has been pointed out in careful analyses, this finding is at variance with the joint null hypothesis that UIP - which pertains to expected exchange rate changes - and unbiased expectations both hold. Frankel has termed this composite the "unbiasedness hypothesis", and it is this proposition that has been widely violated in the empirical literature.

Interestingly, there has been a resurgence of attention over the past decade to the various aspects of how interest rates and exchange rates are linked by arbitrage conditions. This phenomenon is attributable in part to the accumulation of new data for different maturities, the emergence of new markets, and the availability of alternative measures of expectations. Hence, this is a good opportunity to once again review the literature on this subject, with the last such review now a decade old (Engel, 1996).

This paper surveys several of the interesting developments that have taken place in the past decade in the study of uncovered interest parity under the current float. ${ }^{1}$ These include (1) re-evaluation of how well the standard unbiasedness regressions do in the recent period, (2) assessment of how well these regressions perform at the long horizon, (3) investigation of long-horizon uncovered interest parity using survey-based data, and (4) testing of the unbiasedness hypothesis in emerging markets.

\section{A review of the unbiasedness hypothesis}

If the conditions for risk-free arbitrage exist, the log ratio of the forward to the spot exchange rate will equal the interest differential between assets with otherwise similar characteristics measured in local currencies,

$$
f_{t, t+k}-s_{t}=\left(i_{t, k}-i_{t, k}^{*}\right)
$$

where $s_{t}$ is the price of foreign currency in units of domestic currency at time $t, f_{t, t+k}$ is the forward value of $s$ for a contract expiring $k$ periods in the future (both in logs), $i_{t, k}$ is the $k$-period yield on the domestic instrument, and $i_{t, k}^{*}$ is the corresponding yield on the foreign instrument. The left-hand side of Eq. (1) is often called the forward discount.

Eq. (1) is a risk-free arbitrage condition that holds regardless of investor preferences. To the extent that investors are risk averse, however, the forward rate can differ from the expected future spot rate by a premium that compensates for the perceived riskiness of holding domestic versus foreign assets. The risk premium, $\eta$, is defined as:

$$
f_{t, t+k}=s_{t, t+k}^{\mathrm{e}}+\eta_{t, t+k} \text {. }
$$

Substituting Eq. (2) into Eq. (1) then allows the expected change in the exchange rate from period $t$ to period $t+k$ to be expressed as a function of the interest differential and the risk premium:

$$
\Delta s_{t, t+k}^{\mathrm{e}}=\left(i_{t, k}-i_{t, k}^{*}\right)-\eta_{t, t+k}
$$

\footnotetext{
${ }^{1}$ This study does not address longer historical periods, such as that analyzed by Lothian and Wu (2003), even though their results can shed light upon the failure to verify unbiasedness in the post-Bretton Woods era. In addition, it does not focus primarily on time series concerns that recast the results regarding the unbiasedness hypothesis, such as those by Baillie and Bollerslev (2000), Zivot (2000) and Maynard and Phillips (2001).
} 
Narrowly defined, UIP refers to the proposition embodied in Eq. (3) when the risk premium is zero. UIP would hold if investors are risk-neutral investors, or the underlying bonds are perfect substitutes. ${ }^{2}$ In this case, the expected exchange rate change equals the current interest differential. Eq. (3) is not directly testable, however, in the absence of observations on market expectations of future exchange rate movements. To make UIP testable, it is tested jointly with the assumption of rational expectations. Using the rational expectations methodology, future realizations of $s_{t+k}$ will equal the value expected at time $t$ plus a white-noise error term $\xi_{t, t+k}$ that is uncorrelated with all information known at $t$, including the interest differential and the spot exchange rate:

$$
s_{t+k}=s_{t, t+k}^{\mathrm{re}}+\xi_{t, t+k}
$$

Then, one obtains what is commonly, if somewhat misleadingly, known as the UIP regression

$$
\Delta s_{t, t+k}=\left(i_{t, k}-i_{t, k}^{*}\right)-\eta_{t, t+k}+\xi_{t, t+k},
$$

where the left hand side of Eq. (5) is the realized change in the exchange rate from $t$ to $t+k$.

According to the unbiasedness hypothesis, the last two terms in Eq. (5) are assumed to be orthogonal to the interest differential. Thus, in a regression context, the estimated parameter on the interest differential will have a probability limit of unity in the following regression:

$$
\Delta s_{t, t+k}=\alpha+\beta\left(i_{t, k}-i_{t, k}^{*}\right)+\varepsilon_{t, t+k} .
$$

The combined assumptions of no risk premium in Eq. (3) (i.e. that UIP holds) and rational expectations is sometimes termed the "risk-neutral efficient-markets hypothesis" (RNEMH). In this case, the disturbance in Eq. (6) becomes simply the rational expectations' forecast error $\xi_{t, t+k}$, which by definition is orthogonal to all information known at time $t$, including the interest differential.

Unbiasedness is a weaker condition than RNEMH. All that is required is that any risk premium and/or non-rational expectations error be uncorrelated with the interest differential, while the RNEMH requires in addition that no other regressors known at time $t$ have explanatory power. ${ }^{3}$

Estimates of Eq. (6) using values for $k$ that range up to 1 year typically reject the unbiasedness restriction on the slope parameter. The survey by Froot and Thaler (1990), for instance, finds an average estimate for $\beta$ of -0.88 . $^{4}$

Table 1 updates estimates of Eq. (6) for the period 1980Q1-2000Q4. The exchange rates of all six foreign countries were expressed in terms of U.S. dollars, and the 3-, 6-, and 12-month movements in exchange rates were regressed against differentials in euro currency yields of the corresponding maturity. Estimation using the 6- and 12-month horizon data at a quarterly frequency led to overlapping observations, inducing (under the rational expectations null hypothesis) moving average (MA) terms in the residuals. Instead of following Hansen and Hodrick (1980), we use the Generalized Method of Moments (GMM) estimator of Hansen (1982) to

\footnotetext{
${ }^{2}$ Note that some approximations and simplifying assumptions have been made in order to arrive at this expression. See Engel (1996).

${ }^{3}$ The constant term may reflect a constant risk premium demanded by investors on foreign versus domestic assets. Default risk could play a similar role, although the latter possibility is less likely because tests of UIP (as well as CIP) generally use returns on assets issued in offshore markets by borrowers with comparable credit ratings.

${ }^{4}$ Similar results are cited in surveys by MacDonald and Taylor (1992) and Isard (1995).
} 
Table 1

Short-horizon estimates of $\beta$

$$
\Delta s_{t, t+k}=\alpha+\beta\left(i_{t, k}-i_{t, k}^{*}\right)+\varepsilon_{t, t+k}
$$

\begin{tabular}{|c|c|c|c|}
\hline \multirow[t]{2}{*}{ Currency } & \multicolumn{3}{|l|}{ Maturity } \\
\hline & $3 \mathrm{mo}$. & $6 \mathrm{mo}$. & 12 mo. \\
\hline Deutschemark & $-0.809 *(1.134)$ & $-0.893 * * *(0.760)$ & $-0.587 * * *(0.642)$ \\
\hline Japanese yen & $-2.887 * * *(0.997)$ & $-2.926 * * *(0.777)$ & $-2.627 * * *(0.747)$ \\
\hline U.K. pound & $-2.202 * * *(1.086)$ & $-2.046^{* * *}(1.036)$ & $-1.418 * * *(1.041)$ \\
\hline French franc & $-0.179(0.904)$ & $-0.154(0.825)$ & $-0.009(0.853)$ \\
\hline Italian lira & $0.518(0.606)$ & $0.635(0.670)$ & $0.681(0.770)$ \\
\hline Canadian dollar & $-0.477 * * *(0.513)$ & $-0.572 * * *(0.419)$ & $-0.610 * * *(0.557)$ \\
\hline Constrained panel $^{\mathrm{a}}$ & $-0.757 * * *(0.374)$ & $-0.761 * * *(0.345)$ & $-0.536 * * *(0.369)$ \\
\hline
\end{tabular}

Notes: point estimates from the regression in Eq. (6) (serial correlation robust standard errors in parentheses, calculated assuming 2(k-1) moving average serial correlation, following Cochrane, 1991). Sample is 1980Q1-2000Q4. $*(* *)[* * *]$ Different from null of unity at $10 \%(5 \%)[1 \%]$ marginal significance level.

Source: Chinn and Meredith (2004).

${ }^{\text {a }}$ Fixed effects regression. Standard errors adjusted for serial correlation (assumes $k-1$ moving average serial correlation, cross averaging across currency pairs).

correct the standard errors of the parameter estimates for moving average serial correlation of order $(k-1)$ (i.e., MA(1) in the case of 6-month data and MA(3) in the case of 12-month data). We assume a lag order of $2 \times(k-1)$ following Cochrane (1991).

The results confirm the failure of the unbiasedness hypothesis over short horizons, similar to findings obtained in other studies. ${ }^{5}$ At each horizon, four of the six estimated coefficients have the "wrong" sign relative to the unbiasedness hypothesis. The average coefficient is around -0.8 , similar to the value in the survey by Froot and Thaler (1990). Panel estimation with slope coefficients constrained to be identical across countries yields estimates ranging from about -0.76 at the 3 -month horizon to -0.54 at the 12 -month horizon. In most cases it is possible to reject the hypothesis that $\beta$ equals unity; in cases where UIP cannot be rejected, the standard errors of the estimated parameters are quite large. All of the adjusted $R^{2}$ statistics (not reported) are very low, and occasionally negative. Fig. 1 provides the time series plot, and a scatter plot of this result for the DM/dollar rate at the 1-year horizon.

Is this bias disappearing over time? Interestingly, while there is considerable variation over time in the point estimates of $\beta$, in general there is little evidence that the bias is becoming less pronounced. Breaking the 1980Q1-2000Q4 sample into three equal sub-periods, Chinn and Meredith (2005) re-estimated Eq. (6) for the 3-month horizon. The point estimates are displayed in Fig. 2. For each currency, the three bars denote the $\beta$ point estimates for the 1980Q1-1986Q4, 1987Q1-1993Q4 and 1994Q1-2000Q4 periods, respectively. Statistically significant deviations from the $\beta=1$ null hypothesis are denoted by asterisks (since the data are sampled at a quarterly frequency, the issue of overlapping horizons does not arise in this context).

As is made apparent by the patterns in Fig. 2, there are many statistically significant deviations from the $\beta=1$ in the latest 7 -year period. Moreover, the point estimates are more negative

\footnotetext{
${ }^{5}$ The bias in the forward rate is viewed as exploitable by market participants; see Rosenberg (2002: 72-76) and Yilmaz (2005).
} 

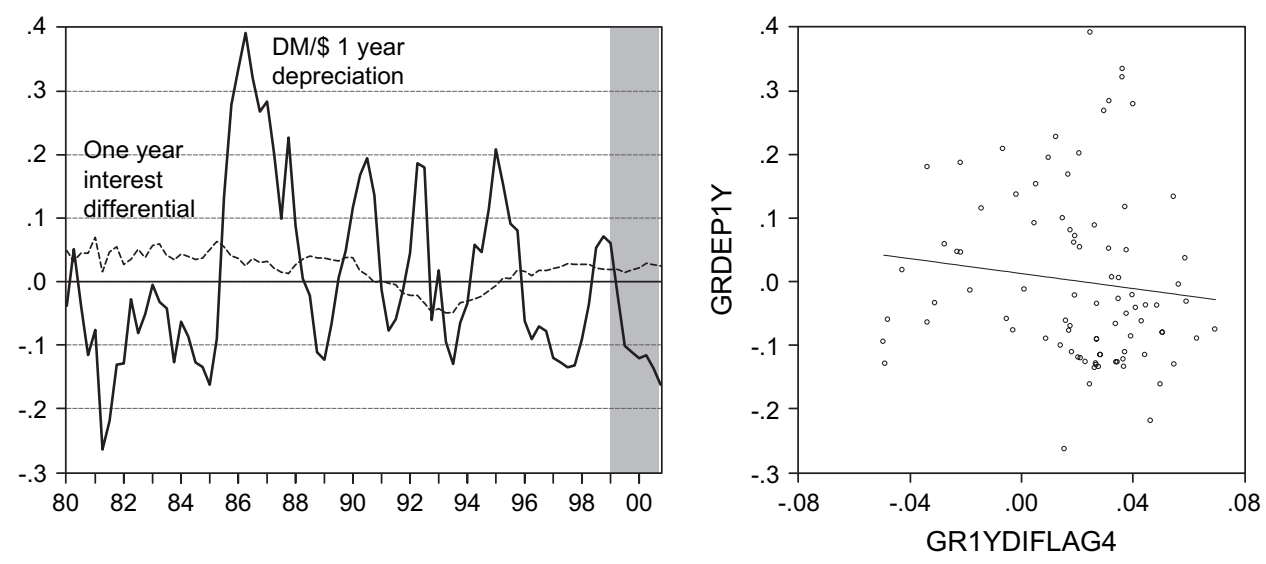

Fig. 1. One-year DM/US\$ depreciation and 1-year offshore interest differential.

in the latter period than in the earliest, with the exception of the U.K. pound/U.S. dollar rate. Thus, in contrast with some other studies, one can conclude that the bias in interest differentials has not disappeared at the short horizon. ${ }^{6}$

Since the sample examined in these regressions ends in 2000, one may wonder whether the advent of the euro has changed matters. Frankel and Poonawala (2004) address this question. They report that over the $1996 \mathrm{~m} 12-2004 \mathrm{~m} 04$ period, a regression of the ex post depreciation on the 1-month forward discount ${ }^{7}$ yields a coefficient of -5.6 . The null hypothesis of a unit coefficient is with a very high level of statistical significance against the null of a coefficient of unity. ${ }^{8}$

\section{The long horizon}

Most of the literature on uncovered interest parity has been of necessity focused on short maturities, although nothing in the theory necessitates this. ${ }^{9}$ That is because the offshore interest rates most likely to conform to the assumptions necessary for interest parity tests have been mostly of maturities less than a year. Data of comparable quality for longer horizon instruments generally are much less readily available. In particular, it is difficult to obtain longer term rates in offshore markets on thickly traded instruments of a known fixed maturity. Moreover, the onshore instruments may be subject to differences in tax regime, capital controls, etc., such that CIP might be violated. Nonetheless, based on the findings by Popper (1993) that covered

\footnotetext{
${ }^{6}$ See for instance Baillie and Bollerslev (2000).

${ }^{7}$ Note that for developed economies, where money markets are unconstrained by capital controls, covered interest parity holds so that the interest differential equals the forward discount. Hence, in these instances, forward rate bias is the same as bias in the interest differential.

${ }^{8}$ I have skirted issues of nonlinearity. Huisman et al. (1998) argue that when the forward discount is large in absolute value, it is a good predictor of subsequent exchange rate movements. Papers by Flood and Rose (1996, 2002), Lothian and Wu (2003), Baillie and Kiliç (2006), and Sarno et al. (2005) have a similar flavor. The latter extend Lyons' (2001) argument that institutionally set limits to speculation induce nonlinearities in the forward/spot relationship.

${ }^{9}$ Indeed, Chaboud and Wright (2005) examine the extreme short end of the maturity spectrum (intraday) and find that unbiasedness holds better than at the typically examined horizons.
} 


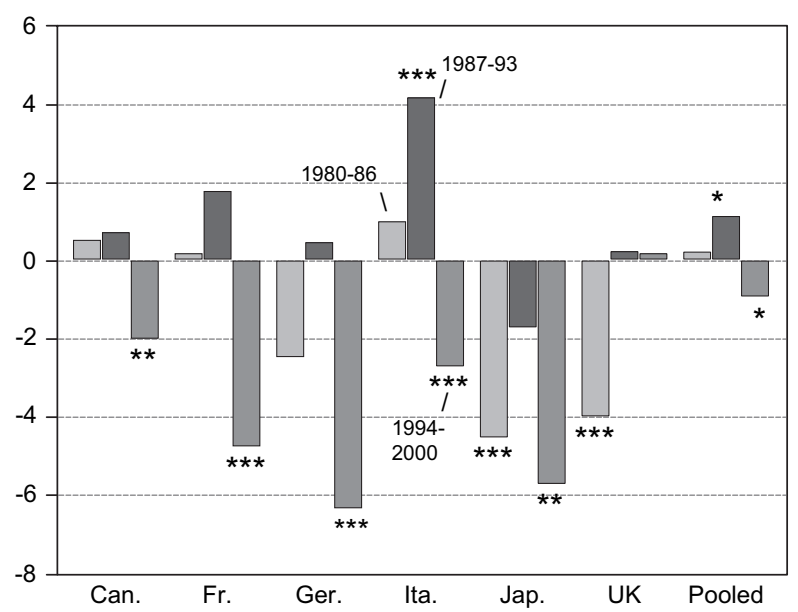

Fig. 2. Three-month beta coefficients for sub-periods. Source: Chinn and Meredith (2005).

interest differentials at long maturities are not appreciably greater than those for short (up to 1 year) maturities, we do not expect that rejections of long-horizon UIP will be driven by deviations from CIP. Another problem is that the interest rate series with given maturities that conform to depreciations of specific horizons must be estimated. So too must the zero-coupon yields that would be most consistent with Eq. (6).

Fortunately, these data deficiencies will tend to bias the coefficient estimates toward zero, so that our tests can be construed to be conservative. This is because if the long-term interest rate series exhibit more "noise" than those used for short-horizon tests of UIP, for conventional errors-in-variables reasons one would expect the coefficient on the interest differential in these regressions to be biased toward zero, and away from its hypothesized value of unity.

In Table 2, the long-horizon estimates for Japan, Germany, the U.K., and Canada are estimated synthetic "constant maturity" 10 -year yields obtained by interpolation of the yield curve of outstanding government securities. Specifically, the 10-year change in the exchange rate versus the dollar for the other six currencies is then regressed on the 10-year lagged differential in the associated bond yield. ${ }^{10}$ Given that generalized floating began in 1973, after allowing for the 10-year lag on the interest differential, the available estimation period consisted of 1983Q1-2004Q4. The estimated slope parameters are much closer to unity than the corresponding short-horizon regressions.

Supporting evidence can be obtained, at the cost of imposing homogeneity on the relationship, by using a panel regression. The point estimate from this regression is 0.709 . The addition of nearly 6 years worth of data has not appreciably changed the results obtained by Meredith and Chinn (1998), namely a panel estimate of 0.708 .

The exercise is repeated with constant-maturity 5-year yields for Germany, the U.K., Canada, and the U.S. over the 1980Q1-2004Q4 period. The results reported in Table 3 are again

\footnotetext{
${ }^{10}$ The serial correlation problem becomes a potentially serious issue as the number of overlapping observations increases rapidly with the instrument maturity. One way to overcome the problem is to use only non-overlapping data; however, this procedure amounts to throwing away information. Boudoukh and Richardson (1994) argue that, depending upon the degree of serial correlation of the regressor and the extent of the overlap, using overlapping data is equivalent to using between 3 and 4.5 times the number of observations available otherwise.
} 
Table 2

Ex post depreciation and 5-year government bond yields

\begin{tabular}{lllll}
\hline & $\hat{\alpha}$ & $\hat{\beta}$ & Reject $H_{0}: \beta=1$ & $R^{2}$ \\
\hline Deutschemark & $-0.005(0.010)$ & $0.902(0.532)$ & & 0.07 \\
U.K. pound & $0.001(0.009)$ & $0.515(0.311)$ & 0.02 & 100 \\
Canadian dollar $_{\text {Constrained panel }^{\mathrm{a}}}$ & $-0.007(0.005)$ & $0.512(0.332)$ & 0.02 & 100 \\
\hline
\end{tabular}

Notes: point estimates from the regression in Eq. (6) (serial correlation robust standard errors in parentheses, using a bandwidth equal to $2 \times(k-1))$.

Sample period: 1980Q1-2004Q1. *(**)[***] Different from null hypothesis at 10\%(5\%)[1\%] marginal significance level.

${ }^{a}$ Fixed effects regression. Standard errors adjusted for serial correlation (assumes $k-1$ moving average serial correlation, cross averaging across currency pairs).

quite favorable to the unbiasedness hypothesis: for all three of these currencies, the slope coefficients are statistically indistinguishable from the implied value of unity. The estimate for the Deutschemark is particularly close to unity at 0.870 , while those for the pound and Canadian dollar are closer to zero. However, in no case can one reject either the null of zero or unit slope. Here, the panel estimate is somewhat lower than the 1.010 value recorded in Meredith and Chinn (1998), although the difference is not statistically significant.

While there have been a few other studies of long-horizon unbiasedness, interpretation of their results is problematic. Flood and Taylor (1997) examine 3-year exchange rate changes on yields of government bonds of varying maturities, obtained from the IMF's International Financial Statistics (IFS). Pooled regressions are then estimated for 21 countries over the 1973-1992 period. They obtain a positive coefficient on the interest differential of 0.596, still statistically different from the value of unity, but at least positive. Similarly, Alexius (2001) examines 14 long-term bond rates of varying maturities for the 1957-1997 period, also drawn from IFS. She too finds coefficient estimates much closer to unity. In both instances, the bond data are heterogeneous in terms of maturity (see the discussion in Chinn and Meredith, 2004). Interpretation of the Alexius results is further complicated by the fact that the data span both fixed and floating rate periods. ${ }^{11}$

One interpretation of these results is that the use of long-horizon regressions is another way of circumventing the errors-in-variables problem. In this context, both the measured exchange rate depreciation and interest differentials are imperfect observations on their equilibrium values, which are the true variables of interest. Lothian and Simaan (1998) time-average the data to mitigate this errors-in-variable problem and obtain one of the rare findings in favor of unbiasedness over the 1974-1994 period.

What conclusions can one draw from these results at both the short and long horizons? Because of the large degree of imprecision of the point estimates, it is difficult to make strong conclusions. Moreover, the very small effective sample sizes available in the long-horizon regressions should give one pause for thought. In order to mitigate these concerns, I rely upon the panel regression coefficient estimates (with the requisite caveat that pooling with common coefficients imposes the strong assumption of homogeneity across currency pairs). The pattern of results is portrayed in Fig. 3. Unbiasedness seems to hold better at longer horizons than at

\footnotetext{
${ }^{11}$ The IFS data are somewhat problematic in that the definitions of long-term bonds are even more heterogeneous across countries and over time than the corresponding medium-term bonds.
} 
Table 3

Ex post depreciation and 10-year government bond yields

\begin{tabular}{|c|c|c|c|c|c|}
\hline & $\hat{\alpha}$ & $\hat{\beta}$ & Reject $H_{0}: \beta=1$ & $R^{2}$ & $N$ \\
\hline Deutschemark & $0.001(0.005)$ & $1.025(0.225)$ & & 0.51 & 88 \\
\hline Japanese yen & $0.027(0.011)$ & $0.469(0.202)$ & $* * *$ & 0.10 & 88 \\
\hline U.K. pound & $0.006(0.003)$ & $0.767(0.098)$ & $* * *$ & 0.45 & 88 \\
\hline Canadian dollar & $-0.004(0.003)$ & $0.672(0.138)$ & $* * *$ & 0.09 & 88 \\
\hline Constrained panel $^{\mathrm{a}}$ & - & $0.758(0.168)$ & & 0.56 & 352 \\
\hline
\end{tabular}

Notes: point estimates from the regression in Eq. (6) (serial correlation robust standard errors in parentheses, calculated assuming approximately $2 \times(k-1)$ moving average serial correlation).

Sample period: 1983Q1-2004Q4.* (**)[***] Different from null of unity at 10\%(5\%)[1\%] marginal significance level.

${ }^{a}$ Fixed effects regression. Standard errors adjusted for serial correlation (assumes $k-1$ moving average serial correlation, cross averaging across currency pairs).

shorter. This interpretation seems to be borne out by Cheung et al.'s (2005) finding that interest parity predicts exchange rates better at long horizons than at short.

Chinn and Meredith (2004) explain the divergence in short- and long-horizon results by appealing to a monetary reaction function that responds to exchange rate changes. The approach broadly follows the mechanism first suggested by McCallum (1994), and re-interpreted econometrically by Anker (1999) and Kugler (2000). However, Chinn and Meredith explain the pattern of estimates by appealing to a term structure that links short- to long-maturity bonds; since the monetary authority can only directly affect the short rate, and indirectly the long rate, there is less endogeneity of the long-term interest differential.

This interpretation can be re-interpreted in an econometric framework following Moore (1994) and Villanueva (2005). Chinn and Meredith (2005) show that long-term rates are more weakly exogenous than short-term rates, and that this can explain the divergence in results in a statistical sense.

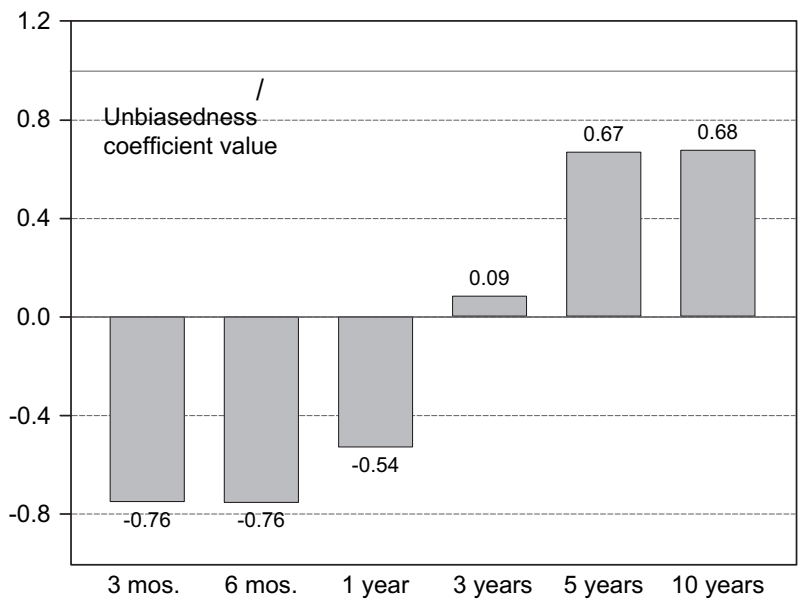

Fig. 3. Panel beta coefficients at different horizons. Notes: up to 12 months, panel estimates for 6 currencies against US\$, euro deposit rates, 1980Q1-2000Q4; 3-year results are zero-coupon yields, 1976Q1-1999Q2; 5 and 10 years, constant yields to maturity, 1980Q1-2000Q4 and 1983Q1-2000Q4. Sources: 3, 6, 12 months, 5 and 10 years from Chinn and Meredith (2004); 3 years, author's calculations using data supplied by Geert Bekaert. 
Of course, other explanations have been forwarded. One explanation is an intertemporal version of the "preferred habitat model". In this case, short- and long-term bond markets are segmented from each other (Lim and Ogaki, 2003). A finding consistent with this approach is provided by Alexius and Sellin (2001). They show that short-horizon holding period returns on long-term bonds do not exhibit bias in predicting short-horizon exchange rate changes. Whether the presence of segmentation is a plausible assumption in an era of highly integrated financial markets is yet to be resolved. ${ }^{12}$

A different - although not necessarily mutually exclusive - explanation is that exchange rate expectations differ at short and long horizons, as suggested by Frankel and Froot (1987), as well as Froot and Ito (1989). This of course cannot be addressed in the framework of the rational expectations methodology, but can be once one appeals to alternative measures of expectations.

\section{Measured expectations versus rational expectations}

It is important to recall that, in fact, uncovered interest parity properly defined as relating to expected depreciation, is untestable. Estimation of the standard UIP regression equation relies upon the rational expectations methodology embodied in Eq. (4). Of course, reliance upon the assumption of mean zero expectational errors is by no means uncontroversial. In a number of papers, Froot and Frankel (1989) demonstrate that the standard tests for UIP yield radically different results when one uses survey-based measures of exchange rate depreciation. They find that most of the variation of the forward discount appears to be related to expected depreciation, rather than a time varying risk premium, thereby lending credence to UIP. [Since covered interest parity holds for these currencies, the forward discount is equivalent to the interest differential.]

Chinn and Frankel (1994a,b, 2002) document the fact that it is difficult to reject UIP for a broader set of currencies, when using forecasts provided by the Currency Forecasters' Digest $(C F D)$, although there is some evidence of a risk premium at the 12-month horizon. Chinn and Frankel interpret the differing results as arising from a wider set of currencies - they examine 17 currencies as opposed to the 5 or so examined by Frankel and Froot - where the assumption of perfect substitutability of debt instruments is less likely to hold.

If the relaxation of the rational expectations methodology can produce such contrasting results, it is of interest to investigate whether the finding of uncovered interest parity also pertains to longer horizons. In order to investigate this, I estimate the following regression:

$$
\Delta \hat{s}_{t, t+k}^{\mathrm{e}}=\alpha+\beta\left(i_{t, k}-i_{t, k}^{*}\right)+\tilde{\varepsilon}_{t, t+k}
$$

where $\hat{s}_{t, t+k}^{\mathrm{e}} \equiv \hat{s}_{t, t+k}^{\mathrm{e}}-s_{t}$ is the expected depreciation implied by the geometric mean of survey data on future spot exchange rates. In this case, the error term, $\tilde{\varepsilon}_{t, t+k}$ need not be mean zero and iid.

I use proxies for 5-year ahead expectations of spot rates, obtained from $C F D$ and its successors Financial Times Currency Forecaster and FX4casts. Specifically, FX4casts reports in late February, May, August and November 1994 the end-of-1998 forecast spot rate. The February forecast is only slightly less than 5 years ahead.

\footnotetext{
${ }^{12}$ New versions of segmented markets hypotheses go under the rubric of "limited participation" models. See for instance Mizrach and Occhino (2004), Alvarez et al. (2001), and Lahiri et al. (2003).
} 
Table 4

Expected depreciation and 5-year government bond yields

\begin{tabular}{lllrr}
\hline & $\hat{\alpha}$ & $\hat{\beta}$ & Reject $H_{0}: \beta=1$ & $R^{2}$ \\
\hline Deutschemark & $-0.031(0.010)$ & $0.219(0.731)$ & -0.11 & 10 \\
U.K. pound & $-0.002(0.011)$ & $1.613(0.570)$ & 0.36 & 10 \\
Canadian dollar $_{\text {Constrained panel }}^{\mathrm{a}}$ & $0.007(0.005)$ & $0.724(0.378)$ & 0.13 & 10 \\
\hline
\end{tabular}

Notes: point estimates from the regression in Eq. (7) (serial correlation robust standard errors in parentheses, using a bandwidth equal to 2).

Sample period: 1988Q4-1997Q4. *(**)[***] Different from null hypothesis at 10\%(5\%)[1\%] marginal significance level.

${ }^{a}$ Fixed effects regression (heteroskedasticity robust standard errors).

The results for regressions estimated over the 1988Q4-1997Q4 period are reported in Table 4. They indicate that, while the point estimates are not always close to unity, it is not possible to reject the null hypothesis that the coefficient is unity. Since there are so few observations in each time series regression, one should rely upon the panel regression estimates. The point estimate of 0.74 is not statistically significantly different from unity, and remarkably close to the estimate for ex post depreciation.

\section{Unbiasedness in emerging markets}

The last two decades have witnessed a rapid opening up of many money and capital markets in what are called the emerging markets. In general, there is little reason to believe that the unbiasedness hypothesis, or even uncovered interest parity, should hold in such markets. Even with liberalization, some capital controls are usually extant, and as a consequence, at least political risk should exist. To fix concepts:

$$
\left(i_{t, k}-i_{t, k}^{*}\right) \equiv\left[i_{t, k}-i_{t, k}^{*}-\left(f_{t, t+k}-s_{t}\right)\right]+\left(f_{t, t+k}-s_{t+k}^{\mathrm{e}}\right)+\Delta s_{t+k}^{\mathrm{e}} .
$$

The objects on the right-hand side of Eq. (1) are of interest in their own right. The term in square brackets is called the covered interest differential and the term $\left(f_{t, t+k}-s_{t+k}^{\mathrm{e}}\right)$ is sometimes labeled the exchange risk premium. The covered interest differential is identified as the political risk associated with capital controls or the threat of their imposition (Dooley and Isard, 1980). When both of these terms are zero, then the interest differential equals expected depreciation. Re-arranging, this means the uncovered interest differential equals the sum of political risk and exchange risk

$$
\left(i_{t}^{k}-i_{t}^{k^{*}}\right)-\Delta s_{t+k}^{\mathrm{e}} \equiv\left[i_{t}^{k}-i_{t}^{k^{*}}-\left(f_{t, t+k}-s_{t}\right)\right]+\left(f_{t, t+k}-s_{t+k}^{\mathrm{e}}\right) .
$$

Frankel (1984) terms a zero covered interest differential a condition of perfect capital mobility, in the sense that movements of financial capital are unimpeded. The exchange risk premium is a measure to which these assets are viewed as being indistinguishable to the representative investor, either because the profile of their returns is identical, or because investors are risk neutral. Regression equation (6) (unbiasedness) or (7) (UIP) yields a coefficient of unity under the null if political and exchange risks are both zero. ${ }^{13}$

\footnotetext{
${ }^{13}$ Tests of UIP for developing economies are less common, mainly because of the dearth of exchange rate expectations data. Chinn and Frankel (1994a) conducted UIP tests for selected East Asian emerging markets using survey data. Unfortunately, data limitations preclude one from undertaking this approach for these economies.
} 
One early study of the unbiasedness hypothesis concludes that for emerging market interest differentials against the U.S., unbiasedness tends to hold better when in the emerging economy the inflation rate and inflation volatility are high, or per capita incomes are low (Bansal and Dahlquist, 2000).

Frankel and Poonawala (2004) examine a number of emerging market currencies, using the regression:

$$
\Delta s_{t, t+k}=\alpha+\beta\left(f_{t, k}-s_{t}\right)+\bar{\varepsilon}_{t, t+k},
$$

where the term in parentheses may or may not equal the on-shore interest differential. Using 1month forwards, they find that on average the estimated $\beta$ is positive, albeit much smaller than unity. Their results are reported in Table 5.

Fig. 4 presents a scatter plot of ex post depreciations against 1-month forward discounts for Czech Republic, Hong Kong, Hungary, India, Indonesia, Kuwait, Mexico, Philippines, Saudi Arabia, Singapore, and South Africa. The figure clearly indicates a small upward slope.

What about longer horizons? Ideally, one would like longer term government bond rates, analogous to those examined in Section 3. Unfortunately, most emerging market governments could not borrow in their own currency, until very recently. Consequently, Madarassy and Chinn (2002) examine the following non-G7 developed countries: Denmark, Finland, Ireland, Norway, Netherlands, Spain, Sweden and Switzerland. Of these, Finland, Ireland, and Spain might be considered emerging.

The long-term data are obtained from the Bank of International Settlements database. Data are available monthly from January 1973 to May 1998, and are converted to quarterly frequency using the observation on the last month of each quarter. Hence, all the results reported below

Table 5

Individual emerging market country regressions (12/31/1996-04/30/2004) coefficients with robust standard errors

$$
s_{t+1}-s_{t}=\alpha+\beta\left(f_{t}-s_{t}\right)+\varepsilon_{t}
$$

\begin{tabular}{|c|c|c|c|c|c|c|c|}
\hline & Dates & $N$ & $\beta$ (S. E.) & $t: \beta=0$ & $t: \beta=1$ & DW & F prob \\
\hline \multicolumn{8}{|c|}{ Emerging and newly industrialized economies } \\
\hline Czech Republic & $12 / 96-4 / 04$ & 88 & $0.4260(0.6604)$ & 0.65 & 0.76 & 1.90 & 0.5206 \\
\hline Hong Kong & $12 / 96-4 / 04$ & 88 & $-0.0439(0.0376)$ & -1.17 & 768 & 2.44 & 0.2468 \\
\hline Hungary & $10 / 97-4 / 04$ & 78 & $0.7541(1.2594)$ & 0.60 & 0.04 & 1.82 & 0.5511 \\
\hline India & $10 / 97-4 / 04$ & 78 & $-0.6181(0.8612)$ & -0.72 & 3.53 & 1.43 & 0.4751 \\
\hline Indonesia & $12 / 96-12 / 02$ & 73 & $0.1456(0.2055)$ & 0.71 & 17.28 & 1.55 & 0.4807 \\
\hline Kuwait & $12 / 96-4 / 04$ & 88 & $0.4050(0.9394)$ & 0.43 & 0.40 & 1.89 & 0.6674 \\
\hline Mexico & $12 / 96-4 / 04$ & 88 & $-0.6399(0.4079)$ & -1.57 & 16.16 & 1.99 & 0.1204 \\
\hline Philippines & $12 / 96-4 / 04$ & 88 & $1.6770(1.7128)$ & 0.98 & 0.16 & 1.87 & 0.3303 \\
\hline Saudi Arabia & $12 / 96-4 / 04$ & 88 & $-0.0831(0.0835)$ & -1.00 & 168.17 & 2.94 & 0.3223 \\
\hline Singapore & $12 / 96-4 / 04$ & 88 & $0.1911(1.2898)$ & 0.15 & 0.39 & 1.86 & 0.8826 \\
\hline South Africa & $12 / 96-4 / 04$ & 88 & $-3.2693(1.8403)$ & -1.78 & 5.38 & 1.74 & 0.0792 \\
\hline Taiwan & $12 / 96-4 / 04$ & 88 & $0.1442(0.5252)$ & 0.27 & 2.65 & 1.75 & 0.7842 \\
\hline Thailand & $12 / 96-4 / 04$ & 88 & $0.9613(0.6853)$ & 1.40 & 0.00 & 1.62 & 0.1643 \\
\hline Turkey & $12 / 96-4 / 04$ & 88 & $-0.0031(0.0284)$ & -0.11 & 1241 & 1.54 & 0.9133 \\
\hline
\end{tabular}

Forecast horizon is 1 month.

Notes: point estimates from the regression in Eq. (6) (robust standard errors in parentheses).

Source: Frankel and Poonawala (2004). 


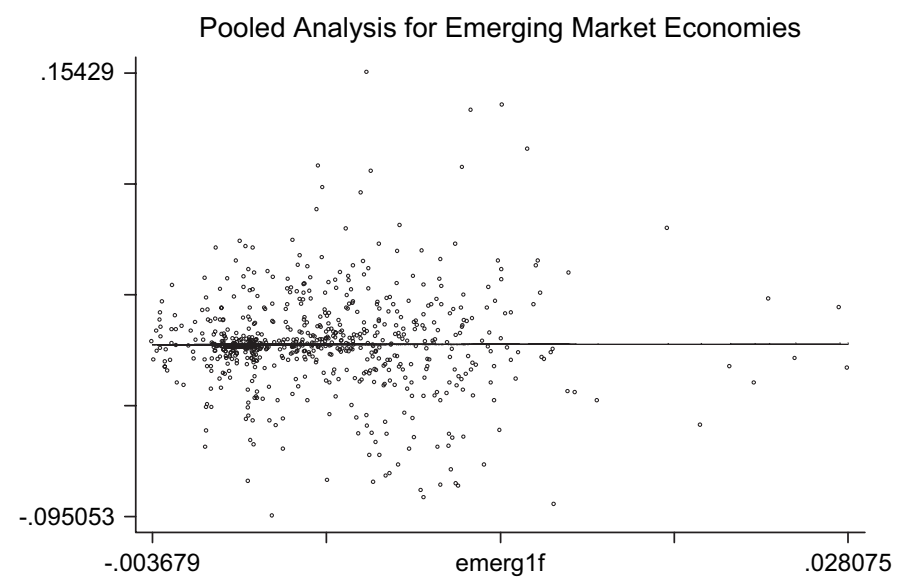

Fig. 4. Scatter plot of 1-month depreciation against 1-month forward discount for 10 emerging market currencies. Source: Frankel and Poonawala (2004).

pertain to regressions on data at the quarterly frequency. The base sample period for each country is between 1973Q1 and 1998Q1.

Table 6 reports the results of the UIP regressions at the 5-year horizon. The Norwegian krone stands out as the regression reports negative coefficients at long horizons also, so by these criteria there is little capital mobility. On the other hand, the Dutch guilder has a positive slope estimate at the long horizon, in contrast to those at the short horizon. Specifically, for the Dutch guilder, the 3 -month horizon coefficient is -1.28 , while the 5 -year horizon coefficient is 0.833 and cannot reject null of unity. Similarly, Sweden also has a positive coefficient three times larger than for the short-horizon. The beta coefficient for Switzerland is statistically equal to unity with a smaller standard error than for the short horizon. In the case of Denmark, the coefficient for the long horizon is large and close to unity, but the null can be rejected. More support for capital mobility is also found at a longer horizon for Netherlands and Sweden, for both of the beta coefficients increase with horizon length.

Table 6

Five-year horizon uncovered interest parity results with ex post spot exchange rates

\begin{tabular}{|c|c|c|c|}
\hline & & $\hat{\alpha}$ & $\hat{\beta}$ \\
\hline Denmark krone & $1983: 2-1994: 2(44)$ & $0.038 * * *(0.011)$ & $1.699 * *(0.294)$ \\
\hline Irish pound & $1985: 1-1993: 4(36)$ & $0.013(0.010)$ & $0.013 *(0.556)$ \\
\hline Netherlands gulden & $1986: 2-1993: 4(30)$ & $0.015 * * *(0.005)$ & $0.833(0.386)$ \\
\hline Norway krone & 1986:1-1994:2 (34) & $-0.014 * *(0.006)$ & $-0.392 * * *(0.280)$ \\
\hline Spanish peseta & & - & - \\
\hline Sweden krona & 1987:1-1994:2 (30) & $-0.006(0.016)$ & $0.600(0.471)$ \\
\hline Swiss franc & $1979: 1-1994: 2(60)$ & $-0.011 * * *(0.003)$ & $1.023(0.074)$ \\
\hline
\end{tabular}

Notes: point estimates from the regression in Eq. (6) (serial correlation robust standard errors in parentheses, calculated assuming approximately $(k-1)$ moving average serial correlation). Reported sample period pertains to the interest rates; to obtain samples pertaining to the ex post depreciations, add 5 years. $\left.*^{* *}\right)[* * *]$ Different from null of unity at $10 \%(5 \%)[1 \%]$ marginal significance level.

Source: Madarassy and Chinn (2002), Table 2. 


\section{Making sense of the results}

One set of findings is relatively easy to explain: the positive coefficients in unbiasedeness regressions in cases where higher inflation rates are involved can be rationalized by the greater predictability in exchange rate trends. The findings of positive coefficients in the short-horizon regressions for Italy in Table 1, as well as in the forward rate regressions for emerging markets documented by Frankel and Poonawala (2004), support this view.

The fact that there appears to be less diversity in the short- and long-horizon UIP regressions using survey data suggests that UIP is not a bad characterization of the data. That is, broadly speaking, interest differentials are offset by expected changes in exchange rates, so that common currency returns are approximately equalized. It is the assumption that forecast errors are mean zero that seems to be at the center of the rejections of the unbiasedness hypothesis. In this sense, the Meredith-Chinn argument regarding endogenous monetary policy is consistent with the presence of long-horizon unbiasedness and survey-based uncovered interest rate parity at all horizons.

Note that the proportion of variation in expected depreciation explained is still very small. Even at the 5-year horizon, the adjusted $R^{2}$ is only $34 \%$, for the UK/dollar rate, and much lower for the other rates. For the DM/dollar rate, it is negative, and the point estimate of the $\beta$ coefficient is only about 0.22 . While this is not statistically significantly different from unity, the results do leave room for a deviation from UIP.

The natural interpretation for a deviation, if such exists, at the long horizons is that there is an exchange risk premium associated with government bonds (as opposed to the offshore rates typically used in UIP analyses). As noted in Chinn and Frankel (2002), if one can reject the null hypothesis that $\beta \leq 0.5$, then one can reject the Fama-Hodrick-Srivastava (Hodrick and Srivastava, 1986) hypothesis that the variation in the expectation of depreciation is less than the variation in the risk premium. Only in the case of the pound/dollar is it possible to reject this hypothesis at anywhere near conventional levels (although the tests are of very low power here).

While the empirical literature on the portfolio balance effect has been generally negative, it may be the case that with the large movements in government debt stocks anticipated in the near future (see Chinn and Frankel, 2004), an exchange risk premium may be identified more readily. Research should be directed toward this end. ${ }^{14}$

\section{Acknowledgments}

This paper has been presented at the Trans-Atlantic Finance Institute conference on Exchange Rates (March 17, 2005, Puerto Rico) organized by M. van Dijk, K. Koedijk and J. Lothian. I thank the discussant Jim Lothian, the conference participants, Yin-Wong Cheung, Michel Galy, Alex Maynard, Dan Thornton, and seminar participants at UW-Milwaukee for comments, and Guy Meredith, Jeffrey Frankel, and Rita Madarassy for allowing me to draw upon joint work. The financial support of faculty research funds of the University of Wisconsin at Madison

\footnotetext{
${ }^{14}$ Research should also investigate the links between the short and long horizons of the term structure of interest rates. Bekaert et al. (2002) conduct a joint test of unbiasedness and the expectations hypothesis of the term structure, since failure of the latter could explain the difference between the findings regarding short and long run unbiasedness.
} 
is gratefully acknowledged. The views contained herein are solely those of the author, and do not necessarily represent those of the institutions he is associated with.

\section{References}

Alexius, A., 2001. Uncovered interest parity revisited. Review of International Economics 9 (3), 505-517.

Alexius, A., Sellin, P., 2001. Exchange rates and long term bonds. Mimeo. Stockholm, Trade Union Institute for Economic Research and Sveriges Riksbank.

Alvarez, F., Lucas, R.E., Weber, W., 2001. Interest rates and inflation. American Economic Review Papers and Proceedings 91, 219-225.

Anker, P., 1999. Uncovered interest parity, monetary policy and time-varying risk premia. Journal of International Money and Finance 18 (6), 835-851.

Baillie, R.T., Bollerslev, T., 2000. The forward premium anomaly is not as bad as you think. Journal of International Money and Finance 19, 471-488.

Baillie, R.T., Kiliç, R., 2006. Asymmetry and nonlinearity in uncovered interest rate parity. Journal of International Money and Finance 25 (2).

Bansal, R., Dahlquist, M., 2000. The forward premium puzzle, different tales from developed and emerging economies. Journal of International Economics 51, 115-144.

Bekaert, G., Wei, M., Xing, Y., 2002. Uncovered interest rate parity and the term structure. NBER Working Paper No. 8795.

Boudoukh, J., Richardson, M., 1994. The statistics of long horizon regressions revisited. Mathematical Finance 4, $103-119$.

Chaboud, A.P., Wright, J.H., 2005. Uncovered interest parity, it works, but not for long. Journal of International Economics 66 (2), 349-362.

Cheung, Y.-W., Chinn, M.D., Garcia Pascual, A., 2005. Empirical exchange rate models of the nineties, are any fit to survive? Journal of International Money and Finance 24, 1150-1175.

Chinn, M.D., Frankel, J.A., 2004. The euro area and world interest rates. Paper presented at conference on Financial Globalization. New York, Federal Reserve Bank of NY.

Chinn, M.D., Frankel, J.A., 2002. Survey data on exchange rate expectations, more currencies, more horizons, more tests. In: Allen, W., Dickinson, D. (Eds.), Monetary Policy, Capital Flows and Financial Market Developments in the Era of Financial Globalisation, Essays in Honour of Max Fry. Routledge, London, pp. $145-167$.

Chinn, M.D., Frankel, J.A., 1994a. Financial links around the Pacific Rim, 1982-1992. In: Glick, R., Hutchison, M. (Eds.), Exchange Rate Policy and Interdependence, Perspective from the Pacific Basin. Cambridge University Press, Cambridge, pp. 17-26.

Chinn, M.D., Frankel, J.A., 1994b. Patterns in exchange rate forecasts for 25 currencies. Journal of Money, Credit and Banking 26 (4), 759-770.

Chinn, M.D., Meredith, G., 2004. Monetary policy and long horizon uncovered interest parity. IMF Staff Papers 51 (3), 409-430.

Chinn, M.D., Meredith, G., 2005. Testing uncovered interest parity at short and long horizons during the Post-Bretton Woods era. NBER Working Paper No. 11077.

Cochrane, J., 1991. Production-based asset pricing and the link between stock returns and economic fluctuations. Journal of Finance 46, 207-234.

Dooley, M.P., Isard, P., 1980. Capital controls, political risk, and deviations from interest rate parity. Journal of Political Economy 88 (2), 370-384.

Engel, C., 1996. The forward discount anomaly and the risk premium, a survey of recent evidence. Journal of Empirical Finance 3, 123-192.

Flood, R.P., Rose, A.K., 1996. Fixes, of the forward discount puzzle. Review of Economics and Statistics 748-752.

Flood, R.B., Rose, A.K., 2002. Uncovered interest parity in crisis. International Monetary Fund Staff Papers 49, $252-266$.

Flood, R.P., Taylor, M.P., 1997. Exchange rate economics, what's wrong with the conventional macro approach? The Microstructure of Foreign Exchange Markets. University of Chicago for NBER, pp. 262-301.

Frankel, J.A., 1984. The Yen/Dollar agreement, liberalizing Japanese capital markets. Policy Analyses in International Economics. Institute for International Economics, 9. 
Frankel, J.A., Froot, K.A., 1987. Using survey data to test standard propositions regarding exchange rate expectations. American Economic Review 77 (1), 133-153.

Frankel, J.A., Poonawala, J., 2004. The forward market in emerging currencies, less biased than in major currencies. Mimeo, Kennedy School of Government, Cambridge, MA.

Froot, K.A., Frankel, J.A., 1989. Forward discount bias, is it an exchange risk premium? Quarterly Journal of Economics 104 (1), 139-161.

Froot, K.A., Ito, T., 1989. On the consistency of short-run and long-run exchange rate expectations. Journal of International Money and Finance 8 (4), 487-510.

Froot, K.A., Thaler, R.H., 1990. Foreign exchange. Journal of Economic Perspectives 4 (3), 179-192.

Hansen, L.P., 1982. Large sample properties of generalized method of moments estimators. Econometrica 50 (4), 10291054.

Hansen, L.P., Hodrick, R.J., 1980. Forward rates as optimal predictors of future spot rates, an econometric analysis. Journal of Political Economy 88, 829-853.

Hodrick, R.J., Srivastava, S., 1986. An investigation of risk and return in forward foreign exchange. Journal of International Money and Finance 3, 5-30.

Huisman, R., Koedijk, K., Kool, C., Nissen, F., 1998. Extreme support for uncovered interest parity. Journal of International Money and Finance 17, 211-228.

Isard, P., 1995. Exchange Rate Economics. Cambridge University Press.

Kugler, P., 2000. The expectations hypothesis of the term structure of interest rates, open interest rate parity and central bank policy reaction. Economics Letters 66, 209-214.

Lahiri, A., Singh, R., Vegh, C., 2003. Segmented asset markets and optimal exchange rate regimes. Mimeo, UCLA.

Lim, H., Ogaki, M., 2003. A theory of the exchange rates and the term structure of interest rates. Rochester Center for Economic Research Working Paper No. 504, University of Rochester, Rochester, NY.

Lothian, J.R., Simaan, Y., 1998. International financial relations under the current float, evidence from panel data. Open Economies Review 9 (4), 293-313.

Lothian, J.R., Wu, L., 2003. Uncovered interest rate parity over the past two centuries. Unpublished Working Paper. Fordham University, New York, NY.

Lyons, R., 2001. The Microstructure Approach to Exchange Rates. MIT Press, Cambridge and London.

MacDonald, R., Taylor, M.P., 1992. Exchange rate economics, a survey. IMF Staff Papers 39 (1), 1-57.

Madarassy, R., Chinn, M.D., 2002. Free to flow? New results on capital mobility amongst the developed countries. Santa Cruz Center for International Economics Working Paper No. 02-20. Santa Cruz, CA.

McCallum, B.T., 1994. A reconsideration of the uncovered interest parity relationship. Journal of Monetary Economics 33, 105-132.

Maynard, A., Phillips, P.C.B., 2001. Rethinking an old empirical puzzle, econometric evidence on the forward discount anomaly. Journal of Applied Econometrics 16 (6), 671-708.

Meredith, G., Chinn, M.D., 1998. Long-horizon uncovered interest rate parity. NBER Working Paper no. 6797.

Mizrach, B., Occhino, F., 2004. The impact of monetary policy on bond returns, a segmented markets approach. Mimeo, Rutgers University, New Brunswick, NJ.

Moore, M.J., 1994. Testing for unbiasedness in forward markets. The Manchester School 62 (Suppl.), 67-78.

Popper, H., 1993. Long-term covered interest parity-evidence from currency swaps. Journal of International Money and Finance 12 (4), 439-448.

Rosenberg, M., 2002. The Deutsche bank guide to exchange-rate determination, a survey of exchange-rate forecasting models and strategies. Deutsche Bank Global Markets Research, New York, NY.

Sarno, L., Valentea, G., Leon, H., 2005. The forward bias puzzle and nonlinearity in deviations from uncovered interest parity, a new perspective. Mimeo, University of Warwick.

Villanueva, O.M., 2005. FX dynamics, limited participation, and the forward bias anomaly. The Financial Review 40, 67-93.

Yilmaz, F., 2005. Dancing on the Curve, Quantitative Currency Analysis. Bank of America, London.

Zivot, E., 2000. Cointegration and forward and spot exchange rate regressions. Journal of International Money and Finance 19, 785-812. 